Original article

\title{
Obesity, dieting, and multiple sclerosis
}

\author{
R.D. Russell ${ }^{\mathrm{a}}$, A. Langer-Gould ${ }^{\mathrm{b}}$, E.G. Gonzales ${ }^{\mathrm{c}}$, J.B. Smith ${ }^{\mathrm{c}}$, V. Brennan ${ }^{\mathrm{a}}$, G. Pereira ${ }^{\mathrm{a}}$, \\ R.M. Lucas ${ }^{\mathrm{d}, \mathrm{e}}$, A. Begley ${ }^{\mathrm{a}}$, L.J. Black ${ }^{\mathrm{a}, *}$ \\ ${ }^{a}$ School of Public Health, Curtin University, Perth, Australia \\ ${ }^{\mathrm{b}}$ Neurology Department, Los Angeles Medical Center, Southern California Permanente Medical Group/Kaiser Permanente, Los Angeles, United States \\ ${ }^{\mathrm{c}}$ Department of Research and Evaluation, Kaiser Permanente, Pasadena, United States \\ ${ }^{\mathrm{d}}$ National Centre for Epidemiology and Population Health, Research School of Population Health, Australian National University, Canberra, Australia \\ ${ }^{\mathrm{e}}$ Centre for Ophthalmology and Visual Science, University of Western Australia, Perth, Australia
}

\section{A R T I C L E I N F O}

\section{Keywords:}

Dietary behavior

Dietary changes

MS Sunshine Study

Multiple sclerosis

Nutrition

\begin{abstract}
A B S T R A C T
Background: Obesity is common in the United States and is associated with a higher risk of relapse and comorbidities, and increased disease progression, in people with MS

Methods: We examined the prevalence of overweight and obesity in the MS Sunshine Study, a matched casecontrol study of multiple sclerosis in Southern California (470 cases, 519 controls). We reported the proportion of participants who adopted a specific diet for nutrition or weight loss purposes, and identified independent predictors of dieting.

Results: In the total population, $32 \%$ and $37 \%$ were overweight and obese, respectively. Case participants were no more likely to adopt a specific diet for nutrition or weight loss purposes than control participants ( $10 \%$ and $11 \%$, respectively). Being obese, younger, female or non-Hispanic were independently associated with dieting. Conclusion: Despite the evidence that obesity can worsen MS prognosis, and the high prevalence of overweight/ obesity, case participants were no more likely to adopt a specific diet than control participants. Improved nutrition education may help people with MS make healthy dietary changes for nutrition or weight loss purposes.
\end{abstract}

\section{Introduction}

In the United States (US), $40 \%$ of adults are obese, a trend that is increasing (Hales et al., 2017). Overweight/obesity in people with MS (pwMS) has been associated with greater neuroinflammation (Stampanoni Bassi et al., 2019), relapse risk, and disability progression (Tettey et al., 2017). There is little research exploring the diets adopted by pwMS for nutrition or weight loss purposes. Using data from the MS Sunshine Study, a multi-ethnic matched case-control study in Southern California examining risk factors for MS (Langer-Gould et al., 2018), we aimed to describe the number and proportion of pwMS adopting specific diets after MS symptom onset, and to identify predictors of adopting a specific diet. We hypothesized that the onset of MS symptoms would increase motivation among overweight or obese individuals to change their diet.

\section{Material and methods}

Participants of the 2011-2015 MS Sunshine Study were recruited from the Kaiser Permanente Southern California (KPSC) database of $>4$ million members; detailed methods are described elsewhere (LangerGould et al., 2018). In brief, adult members ( $\geq 18$ years) diagnosed with MS or clinically isolated syndrome within the past 18 months, or those with symptom onset within the past three years, were eligible. Control participants from the KPSC population were matched on age, sex, race/ethnicity, and home KPSC facility (a surrogate measure for socioeconomic status). After written informed consent was obtained, data were collected from structured in-person interviews (race/ethnicity, education), self-administered questionnaire (diets), and the complete electronic health record (body mass index (BMI) at date of symptom onset). The study was conducted in accordance with the Declaration of Helsinki. The protocol was approved by the KPSC Institutional Review Board (IRB 5962).

BMI was categorized as: normal/underweight $\left(<25 \mathrm{~kg} / \mathrm{m}^{2}\right)$; overweight $\left(25-<30 \mathrm{~kg} / \mathrm{m}^{2}\right)$; obese class I $\left(30-<35 \mathrm{~kg} / \mathrm{m}^{2}\right)$, or obese class II $\left(\geq 35 \mathrm{~kg} / \mathrm{m}^{2}\right.$ ). Participants reported start and end dates of specific diets they followed for "nutrition or weight loss purposes", selecting from nine predefined diets (Paleo, South Beach, Perricone, Jenny Craig, Weight Watchers, 17 Day Diet, Jillian Michael's, The Mommy Diet, Nutrisystem), and an open text field for "Other". Participants could

\footnotetext{
* Corresponding author at: School of Public Health, Kent St, Bentley, WA 6102, Australia.

E-mail address: lucinda.black@curtin.edu.au (L.J. Black).
} 
Table 1

Participant characteristics at index date ${ }^{1}$.

\begin{tabular}{lll}
\hline & Cases $(n=470)$ & Controls $(n=519)$ \\
\hline Sex, \% (n) & & \\
Male & $26.8 \%(126)$ & $27.6 \%(143)$ \\
Female & $73.2 \%(344)$ & $72.5 \%(376)$ \\
Age, y, mean (SD) & $37.5(12.6)$ & $37.0(12.7)$ \\
Race/ethnicity,\% (n) & & \\
$\quad$ White & $48.1 \%(226)$ & $45.3 \%(235)$ \\
Black & $21.5 \%(101)$ & $21.0 \%(109)$ \\
Hispanic & $30.4 \%(143)$ & $33.7 \%(175)$ \\
BMI (kg/m2), median (IQR) & $28.1(24.0-33.0)$ & $27.9(24.1-33.5)$ \\
BMI category (kg/m2),\% (n) & & \\
$\quad$ Normal/underweight (<25) & $32.6 \%(153)$ & $29.1 \%(151)$ \\
$\quad$ Overweight (25- <30) & $31.1 \%(146)$ & $33.0 \%(171)$ \\
$\quad$ Obese class I (30-<35) & $17.9 \%(84)$ & $17.2 \%(89)$ \\
$\quad$ Obese class II ( $\geq 35)$ & $18.5 \%(87)$ & $20.8 \%(108)$ \\
Education, $\%$ (n) & & \\
$\quad$ Some college or less & $57.7 \%(271)$ & $53.4 \%(277)$ \\
$\quad$ College or graduate school & $42.3 \%(199)$ & $46.6 \%(242)$ \\
Smoking history (ever smoked),\% (n) & & \\
$\quad$ No & $66.8 \%(314)$ & $74.0 \%(384)$ \\
$\quad$ Yes & $33.2 \%(156)$ & $26.0 \%(135)$ \\
\hline
\end{tabular}

$\mathrm{IQR}$, interquartile range; SD, standard deviation.

1 Date of MS symptom onset (or matched time frame for controls).

select multiple options.

Control participants were considered to have adopted a diet if it occurred between date of symptom onset and interview date of their matched case. Analyses were conducted for the three major racial/ ethnic groups (whites, blacks and Hispanics). Predictors of adopting a specific diet (case/control status, sex, age at symptom onset, education, race, BMI category, smoking history) were investigated using logistic regression models (unadjusted and adjusted). We tested for an interaction between case/control status and BMI using an interaction term in the adjusted model. Data were analysed using Stata Software version 14 (StataCorp, College Station, TX, USA). Statistical significance was defined as $P<0.05$.

\section{Results}

Of the 1193 white, black, and Hispanic participants, 989 (83\%) had complete data on diets and potential predictors. BMI distribution was similar for cases and controls, with a median of $28 \mathrm{~kg} / \mathrm{m}^{2}$ (interquartile range (IQR) $9 \mathrm{~kg} / \mathrm{m}^{2}$ ). Most participants were overweight or obese (Table 1), and the prevalence was similar for cases and controls (overweight $31 \%$ and $33 \%$; obese $36 \%$ and $38 \%$, respectively). Cases and controls had a similar education level ( $58 \%$ and 53\%, respectively, had not completed college). The median time from symptom onset to questionnaire completion was 278 months (IQR, 30 months).

A total of $10 \%(n=46)$ of case participants reported adopting a specific diet for nutrition or weight loss purposes after symptom onset, while $11 \%(n=56)$ of controls did so within the same time frame. There was no independent association between MS status and adopting a specific diet (Table 2). Being overweight/obese, female, or younger were independently associated with significantly increased odds of adopting a specific diet. Hispanics were $46 \%$ and blacks $44 \%$ less likely to adopt a specific diet compared to whites, even after controlling for BMI, sex, age, education and smoking, although this finding did not reach statistical significance in blacks. There was no statistically significant interaction between MS status and BMI category $(P>0.05)$.

The proportion of participants within each BMI category who adopted a specific diet was similar for cases and controls (Fig. 1). The most frequently reported diet was Weight Watchers (cases, $n=16$; controls $n=18$ ).

\section{Discussion}

In the MS Sunshine Study, case participants with recent onset of MS symptoms or diagnosis of MS were no more likely to adopt a specific diet for weight loss or nutrition purposes than control participants, despite a high proportion being overweight or obese. Achieving and maintaining a healthy weight is particularly important for pwMS, since obesity is associated with a higher risk of relapse (Tettey et al., 2017), comorbidities (e.g. diabetes, hypertension, depression), and greater disease progression of MS (Marrie, 2017).

Table 2

Unadjusted and adjusted logistic regression models showing participant characteristics and odds of adopting a specific diet after MS symptom onset $(n=989$; cases, $n=470$; controls, $n=519$ )

\begin{tabular}{|c|c|c|c|c|}
\hline & $\begin{array}{l}\text { Model 1: unadjusted } \\
\text { OR ( } 95 \% \mathrm{CI})\end{array}$ & $\begin{array}{l}\text { Model 2: adjusted } \\
\text { P }\end{array}$ & $\mathrm{aOR}(95 \% \mathrm{CI})^{1}$ & $\mathrm{P}$ \\
\hline Age at symptom onset (years) ${ }^{2}$ & $0.97(0.95,0.99)$ & $<0.001$ & $0.96(0.94,0.98)$ & $<0.001$ \\
\hline \multicolumn{5}{|l|}{ MS status } \\
\hline Control & Reference & & Reference & \\
\hline Case & $0.90(0.59,1.35)$ & 0.605 & $0.94(0.61,1.44)$ & 0.759 \\
\hline \multicolumn{5}{|l|}{ Sex } \\
\hline Male & Reference & & Reference & \\
\hline Female & $4.29(2.13,8.62)$ & $<0.001$ & $4.48(2.20,9.12)$ & $<0.001$ \\
\hline \multicolumn{5}{|l|}{ Race/ethnicity } \\
\hline White & Reference & & Reference & \\
\hline Black & $0.98(0.58,1.68)$ & 0.952 & $0.66(0.38,1.16)$ & 0.150 \\
\hline Hispanic & $0.91(0.57,1.46)$ & 0.691 & $0.54(0.31,0.92)$ & 0.023 \\
\hline \multicolumn{5}{|l|}{ BMI category $(\mathrm{kg} / \mathrm{m} 2)$} \\
\hline Normal/underweight $(<25)$ & Reference & & Reference & \\
\hline Overweight $(25-<30)$ & $1.23(0.66,2.29)$ & 0.518 & $1.71(0.90,3.25)$ & 0.103 \\
\hline Obese class I $(30-<35)$ & $2.65(1.42,4.95)$ & 0.002 & $3.76(1.95,7.23)$ & $<0.001$ \\
\hline Obese class II ( $\geq 35)$ & $3.06(1.68,5.55)$ & $<0.001$ & $3.93(2.11,7.35)$ & $<0.001$ \\
\hline \multicolumn{5}{|l|}{ Education } \\
\hline Some college or less & Reference & & Reference & \\
\hline College or graduate school & $1.07(0.71,1.61)$ & 0.750 & $1.12(0.72,1.75)$ & 0.604 \\
\hline \multicolumn{5}{|l|}{ Smoking history (ever smoked) } \\
\hline No & Reference & & Reference & \\
\hline Yes & $0.72(0.44,1.15)$ & 0.170 & $0.80(0.48,1.35)$ & 0.400 \\
\hline
\end{tabular}

OR: odds ratio; aOR: adjusted odds ratio; CI: confidence interval.

1 All variables included in a single model.

2 Odds ratio is per one-year increase in age. 


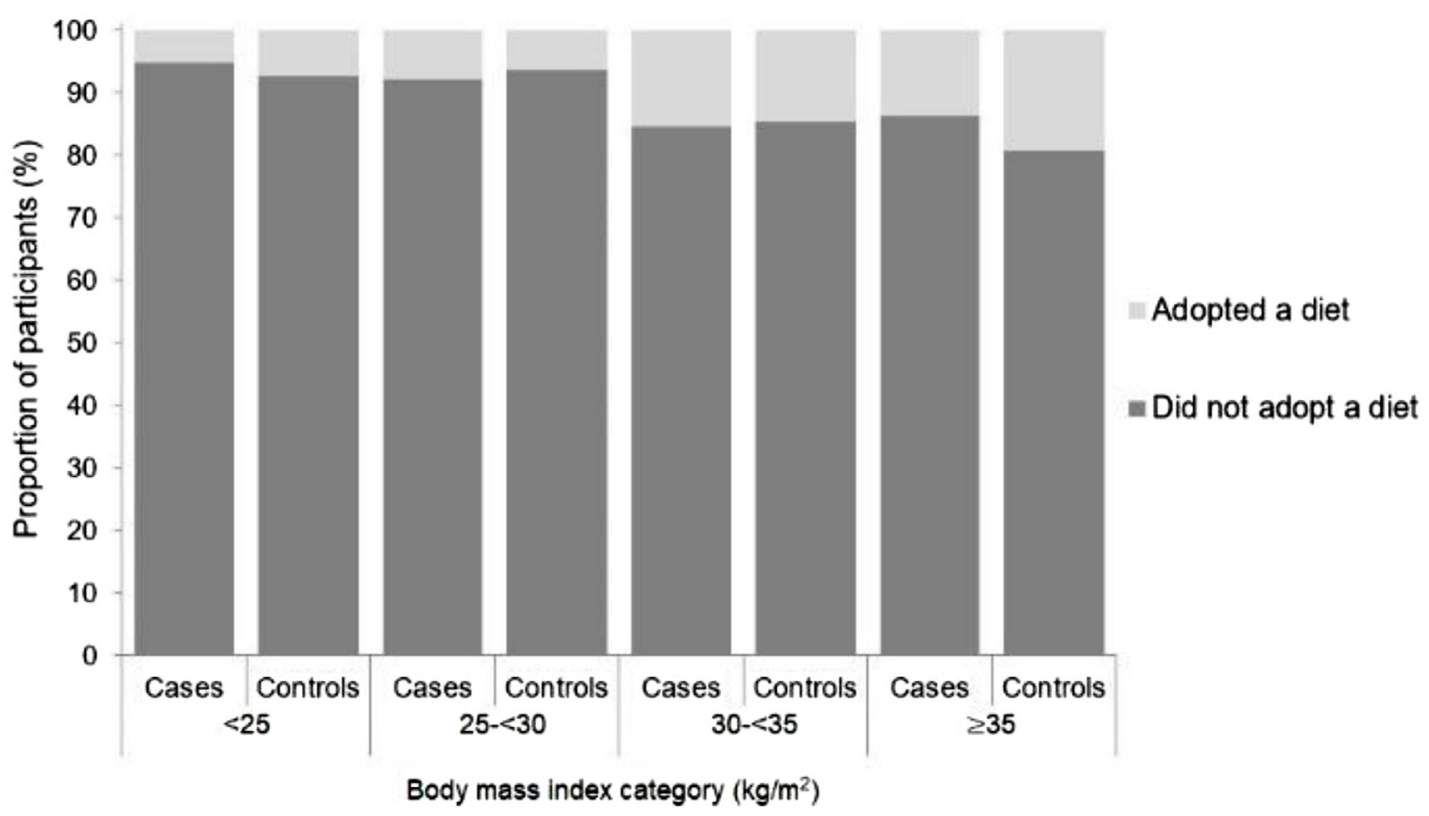

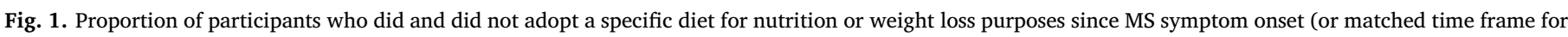
controls).

The proportion of pwMS making dietary modifications in other studies is higher than in our study, ranging from $17 \%$ (Brenton and Goldman, 2016) to approximately 40\% (Fitzgerald et al., 2018; Riemann-Lorenz et al., 2016; Russell et al., 2018). This is likely due to differences in study population, design, and dietary assessment. Previous studies included greater representation of white participants (>90\%) (Fitzgerald et al., 2018; Russell et al., 2018) and prevalent cases (mean disease duration $>7$ years) (Brenton and Goldman, 2016; Riemann-Lorenz et al., 2016), and inquired about any dietary change (Russell et al., 2018), whereas we focused on specific diets for weight loss or nutrition purposes.

Our finding that females were more likely to adopt a weight loss diet than males is consistent with the general population (Martin et al., 2018) and a large survey of prevalent MS cases $(n=6989)$ (Fitzgerald et al., 2018). Likewise, our findings that low-calorie and low-carbohydrate diets were the most popular weight loss diets are consistent with a large survey of pwMS (Fitzgerald et al., 2018).

A limitation of our study is that we did not capture other dietary weight loss efforts participants may have been making after symptom onset or diagnosis, such as reducing the consumption of unhealthy foods. We also cannot exclude the possibility that, with longer duration of follow-up, case participants may have been more likely to engage in specific diets than control participants. Furthermore, we did not examine the relationship between the likelihood of adopting a diet and other variables that may influence dieting, such as MS phenotype, disability status, physical activity, alcohol consumption, comorbidities, and family history of obesity.

\section{Conclusion}

Our findings support the need for MS-focussed nutrition education, with an emphasis on healthy approaches to weight loss for those who are overweight or obese. Only one study has reported the development and feasibility of a dietary education program for pwMS (RiemannLorenz et al., 2016), but it had overall low participant satisfaction and was a largely white study population. Furthermore, there is no evidence regarding the effective elements of dietary education to elicit behavior change or weight loss in pwMS. Such programs, particularly ones targeted to ethnic diversity and males, should be developed and evaluated in randomized controlled trials.

\section{Funding acknowledgments}

The MS Sunshine Study was supported by NIH (NINDS 1R01NS075308 Langer-Gould). RDR would like to acknowledge the support of the Australian Government Research Training Program Scholarship, and an MS Western Australia PhD Top-Up Scholarship. LJB is supported by an MS Research Australia Postdoctoral Fellowship and a Curtin University Research Fellowship. Analysis of diet data from the MS Sunshine Study was funded by MS Western Australia, and collaboration was supported by MS Research Australia Ian Ballard Travel Awards (2015, 2018). RML is supported by an Australian National Health and Medical Research Council Senior Research Fellowship.

\section{Declaration of Competing Interest}

The authors declare not conflicts of interest.

\section{Acknowledgements}

We thank the participants of the MS Sunshine Study.

\section{References}

Brenton, J.N., Goldman, M.D., 2016. A study of dietary modification: perceptions and attitudes of patients with multiple sclerosis. Mult. Scler. Relat. Disord. 8, 54-57. https://doi.org/10.1016/j.msard.2016.04.009.

Fitzgerald, K.C., Tyry, T., Salter, A., Cofield, S.S., Cutter, G., Fox, R.J., Marrie, R.A., 2018. A survey of dietary characteristics in a large population of people with multiple sclerosis. Mult. Scler. Relat. Disord. 22, 12-18. https://doi.org/10.1016/j.msard. 2018.02.019.

Hales, C.M., Carroll, M.D., Fryar, C.D., Ogden, C.L., 2017. Prevalence of Obesity among Adults and Youth: United States. National Center for Health Statistics, Hyattsville, MD, pp. 2015-2016. National Center for Health Statistics data brief, no. 288Retrieved from. https://www.cdc.gov/nchs/data/databriefs/db288.pdf.

Langer-Gould, A., Lucas, R., Xiang, A., Chen, L., Wu, J., Gonzalez, E., ... Barcellos, L., 2018. MS sunshine study: Sun exposure but not vitamin d is associated with multiple sclerosis risk in blacks and hispanics. Nutrients 10 (3), 268. https://doi.org/10.3390/ nu10030268.

Marrie, R.A., 2017. Comorbidity in multiple sclerosis: implications for patient care. Nat. Rev. Neurol. 13 (6). https://doi.org/10.1038/nrneurol.2017.33.

Martin, C.B., Herrick, K.A., Sarafrazi, N., Ogden, C.L., 2018. Attempts to Lose Weight among Adults in the United States. National Center for Health Statistics. Retrieved from, Hyattsville, MD, pp. 2013-2016. NCHS Data Brief, no. 313. https://www.cdc.gov/ nchs/data/databriefs/db313.pdf.

Riemann-Lorenz, K., Eilers, M., von Geldern, G., Schulz, K.-H., Köpke, S., Heesen, C., 
2016. Dietary interventions in multiple sclerosis: development and pilot-testing of an evidence based patient education program. PLoS ONE 11 (10), e0165246. https:// doi.org/10.1371/journal.pone.0165246.

Russell, R.D., Lucas, R.M., Brennan, V., Sherriff, J.L., Begley, A., The Ausimmune Investigator Group,Black, L.J., The Ausimmune Investigator Group, 2018. Reported changes in dietary behavior following a first clinical diagnosis of central nervous system demyelination. Front. Neurol. 9 (161), 1-7. https://doi.org/10.3389/fneur. 2018.00161.

Stampanoni Bassi, M., Iezzi, E., Buttari, F., Gilio, L., Simonelli, I., Carbone, F., ...
Matarese, G., 2019. Obesity worsens central inflammation and disability in multiple sclerosis. Multiple Sclerosis Journal. https://doi.org/10.1177/1352458519853473. [Epub ahead of print].

Tettey, P., Simpson, S., Taylor, B., Ponsonby, A.-.L., Lucas, R.M., Dwyer, T., ... van Der Mei, I.A., 2017. An adverse lipid profile and increased levels of adiposity significantly predict clinical course after a first demyelinating event. Journal of Neurology,

Neurosurgery \& Psychiatry 88 (5), 395-401. https://doi.org/10.1136/jnnp-2016315037 . 